Article

\title{
The Relationship between Whole Grain Intake and Body Weight: Results of Meta-Analyses of Observational Studies and Randomized Controlled Trials
}

\author{
Kevin C. Maki ${ }^{1, *}$, Orsolya M. Palacios ${ }^{1}$, Katie Koecher ${ }^{2}$, Caleigh M. Sawicki ${ }^{3}{ }^{1}$, \\ Kara A. Livingston ${ }^{3}$, Marjorie Bell ${ }^{1}$, Heather Nelson Cortes ${ }^{4}$ and Nicola M. McKeown ${ }^{3}$ \\ 1 Midwest Biomedical Research/Center for Metabolic and Cardiovascular Health, 211 East Lake Street, Suite 3, \\ Addison, IL 60101, USA; opalacios@mbclinicalresearch.com (O.M.P.); mbell@mbclinicalresearch.com (M.B.) \\ 2 General Mills, Inc., 1 General Mills Blvd., Minneapolis, MN 55426, USA; Katie.Koecher@genmills.com \\ 3 Nutritional Epidemiology Program, Jean Mayer USDA Human Nutrition Research Center on Aging, \\ Tufts University, 711 Washington St, Boston, MA 02111, USA; csawic01@exchange.tufts.edu (C.M.S.); \\ Kara.Livingston@tufts.edu (K.A.L.); nicola.mckeown@tufts.edu (N.M.M.) \\ 4 Kyzo Nutrition, LLC, 1612 Boulder Ridge Dr., Bolingbrook, IL 60490, USA; hnelsoncortes@gmail.com \\ * Correspondence: kmaki@mbclinicalresearch.com; 630-469-6600
}

Received: 11 April 2019; Accepted: 27 May 2019; Published: 31 May 2019

\begin{abstract}
Results from some observational studies suggest that higher whole grain (WG) intake is associated with lower risk of weight gain. Ovid Medline was used to conduct a literature search for observational studies and randomized controlled trials (RCTs) assessing WG food intake and weight status in adults. A meta-regression analysis of cross-sectional data from 12 observational studies (136,834 subjects) and a meta-analysis of nine RCTs (973 subjects) was conducted; six prospective cohort publications were qualitatively reviewed. Cross-sectional data meta-regression results indicate a significant, inverse correlation between WG intake and body mass index (BMI): weighted slope, $-0.0141 \mathrm{~kg} / \mathrm{m}^{2}$ per g/day of WG intake (95\% confidence interval (CI): $-0.0207,-0.0077 ; \mathrm{r}=-0.526$, $p=0.0001$ ). Prospective cohort results generally showed inverse associations between WG intake and weight change with typical follow-up periods of five to 20 years. RCT meta-analysis results show a nonsignificant pooled standardized effect size of $-0.049 \mathrm{~kg}(95 \% \mathrm{CI}-0.297,0.199, p=0.698)$ for mean difference in weight change (WG versus control interventions). Higher WG intake is significantly inversely associated with BMI in observational studies but not RCTs up to 16 weeks in length; RCTs with longer intervention periods are warranted.
\end{abstract}

Keywords: whole grains; body weight; body mass index; body composition; obesity; meta-analysis; randomized controlled trials; prospective cohorts; cross-sectional

\section{Introduction}

Whole grains (WG) are grains that contain the entire nut or seed kernel, including the endosperm, bran, and germ, from the plant from which they are produced [1,2]. WG foods are those that are either $100 \%$ whole grain (e.g., WG rolled oats and WG brown rice) or foods that contain some proportion of a whole grain ingredient (e.g., whole grain bread containing whole wheat flour) [1]. WG foods or foods containing significant quantities of WGs tend to be higher in fiber and contain more of other essential nutrients, including iron, zinc, magnesium, selenium, and B vitamins, than refined grains [1]. Data from observational studies consistently indicate a relationship between WG intake and dietary fiber consumption. For example, comparing categories of WG intake in several cohorts in 
the United States and Europe shows that total dietary fiber intake is significantly associated with WG intake such that total fiber intake is generally $50-100 \%$ higher in the top versus the bottom quintile or quartile of whole WG intake [3,4]. WG intake has been associated with healthful eating patterns and lower risk for several morbidities such as cardiovascular disease, diabetes, and obesity [1,5]. The 2015 Dietary Guidelines for Americans (DGA) recommend that at least half of daily grain intake be from WG, and all healthy eating pattern examples, i.e., Healthy U.S.-Style Eating Pattern, Healthy Mediterranean-Style Eating Pattern, and Healthy Vegetarian Eating Pattern, in the DGA report include WG foods [1]. Although daily intakes of total grains are close to recommended amounts, typically, Americans consume excess amounts of refined grains (e.g., white bread, grain-based desserts, white rice, etc.) and do not consume recommended amounts of WG foods (e.g., whole wheat bread, oatmeal, brown rice, etc.) [1].

Findings from observational studies indicate that higher WG intakes are associated with lower risks of weight gain and incident overweight or obesity [6]. In a review by Karl et al. (2012) on the role of WG in body weight regulation, the authors concluded that the studies completed to that point in time had not provided evidence that a hypoenergetic diet that includes 3 to 7 daily servings of WG (48-112 g/day WG) promotes greater weight loss than a control (either no intervention or foods with refined grains) hypoenergetic diet [7]. However, results from some studies have suggested that a hypoenergetic diet including WG-containing foods may be associated with a greater reduction in body fat, particularly abdominal fat, relative to a hypoenergetic, lower WG diet $[7,8]$. Thus, Pol et al. (2013) concluded that WG consumption does not decrease body weight compared with weight of the control group, but a small beneficial effect on body fat may be present [9].

Many WG foods are good sources of dietary fiber [1,10], and WG intake directly correlates with dietary fiber intake in the U.S. [4]. However, since WG intake among average Americans is $<1$ serving/day WG [1], and high quantities of fiber-poor refined grains are consumed daily [11], refined grain-based foods are actually the primary source of dietary fiber in the U.S. [11,12]. Incorporation of fiber into the diet, depending on fiber type, can favorably impact health, including attenuation of blood cholesterol and glucose levels, and improved laxation [13-15]. Certain types of dietary fibers exert physiological effects that may impact weight status. Beta-glucans and resistant starch type 4, for example, have been found to increase satiety $[16,17]$, though more research is needed. In addition, WG-containing foods collectively contain other bioactive components, such as lignans and phytosterols, shown to exert metabolic effects which have potential to influence body weight and adiposity [18-20]. Given that some observational studies report a link between WG intake and body weight, and several WG food components could plausibly affect body weight regulation, the aim of this review was to provide an updated quantitative analysis of data from both observational studies and RCTs examining the relationship of WG intake with body weight status and related variables.

\section{Methods}

\subsection{Literature Searches}

The Preferred Reporting Items for Systematic Reviews and Meta-Analyses guidelines were followed for performing the meta-analyses [21]. A comprehensive literature search was conducted using the Ovid Medline database, which covered studies published from 1946 through January 2018. The search was designed to identify publications of observational studies and RCTs that examined WG intake from WG foods (e.g., oats, quinoa, wild brown rice, etc.) or foods made with WGs (e.g., whole grain breads, whole grain ready-to-eat breakfast cereals, etc.) and not supplements or specific food additives (e.g., dietary fiber supplements). The search strategy used several terms for WG (whole grain, wholegrain, whole-wheat, wild rice, whole rye, buckwheat, oat, etc.). Full search term details are provided in Table S1. 


\subsection{Inclusion and Exclusion Criteria Screening}

Inclusion and exclusion criteria were applied through a three-level screening process. Full inclusion and exclusion criteria and details are provided in Table S2 for observational studies and Table S3 for RCTs. Final inclusion criteria included study conducted in humans, English language, intervention arm (for RCTs) or a primary exposure variable (for observational studies) where whole foods (e.g., WG bread, brown rice, etc.) are the source of WG, and the WG-containing food is independently assessable and not part of a mixed intervention such as a diet that increases fruits, vegetables and WGs simultaneously. For the observational database, a weight-based anthropometric outcome of interest (i.e., body weight, body mass index (BMI), adiposity, fat-free mass, waist circumference) had to have been examined. The final exclusion criteria included animal studies, in vitro studies, studies conducted in children ( $<18$ years) or pregnant women, studies assessing gluten-free and/or oral rehydration interventions or associations, reviews, bibliographies, case reports, letters, and/or no WG intervention or assessment.

To identify publications, one scientist (CS) performed two separate literature searches-one aimed at capturing observational studies and another aimed at capturing intervention studies. Publications identified using the search terms underwent the first level of screening using Abstrackr (http://abstrackr.cebm.brown.edu). Abstract screening was conducted by one scientist (KL or CS). Full texts of all publications identified as potentially eligible from the abstract screening phase were then obtained and reviewed for eligibility (level 2 screening) by one scientist (CS or KL); however, texts that were unclear with respect to eligibility were additionally reviewed by an additional scientist (NM). Studies that were excluded for not meeting eligibility criteria during level 2 screening were reviewed in duplicate prior to final exclusion. All discrepancies were resolved by a scientific team with oversight by NM. After full text reviews were completed, PICO (population, intervention, comparator, and outcome) data and results were extracted from eligible publications into one of two databases (one for intervention studies, one for observational studies) that were created with input from the research team. For the intervention study database PICO information was extracted, and then the database was searched for and restricted to studies with anthropometric outcomes of interest for the meta-analysis [22]. The observational database was created later, with the goal of a meta-analysis already established; thus, entries were only included in the database if they had the anthropometric outcomes of interest (per inclusion criteria stated above). All data were extracted and entered into the respective database by one scientist (NM, KL, or CS) and then reviewed in full for accuracy by a second scientist.

Publications in the two databases then underwent an additional level 3 screening by two scientists (OMP and HNC) to determine eligibility for final inclusion in the meta-analyses presented here. Each scientist independently performed the level 3 screening, and disagreements in the final inclusion/exclusion criteria were discussed among the scientific team until consensus was reached. Additional inclusion criteria and exclusion criteria for level 3 screening for observational studies included screening for publications which specifically assessed a measure of weight $(\mathrm{kg})$ or weight status (BMI) as an outcome measure of interest and studies providing cross-sectional data for methodological consistency. Additional inclusion criteria and exclusion criteria for level 3 screening for RCTs screened for studies which specifically assessed a measure of weight (kg) or weight status (BMI) as an outcome variable and where the intervention was at least 12 weeks in length. If additional anthropometric measurements, e.g., whole-body adiposity, waist circumference, fat-free mass, etc., were also part of a study's outcome assessment for any of the observational studies or the RCTs, baseline data, and in the case of RCTs, end-of-treatment data, were also recorded for potential secondary analyses.

\subsection{Meta-Regression Analysis of WG Intake: Cross-Sectional Studies}

A meta-regression analysis was performed on results of the observational studies to evaluate cross-sectional associations, which applied several assumptions. When mean or median WG intake for each category of WG intake was reported, this value was used in the analysis. When intake was not reported ( $n=4$ studies from 3 publications) $[3,23,24]$, the midpoint of the range of values reported within 
a category was employed. For the study reported by Albertson et al. (2016), WG intake was presented in categories consisting of 0 servings/day, $>0$ to $<1$ servings/day, or $\geq 1$ serving/day [23]. The $>0$ to $<1$ servings/day was estimated to be equivalent to $0.1 \mathrm{~g} /$ day to $15.9 \mathrm{~g} /$ day and the $\geq 1$ serving/day was estimated to be equivalent to $\geq 16 \mathrm{~g} /$ day. WG intake in the highest category of $\geq 1$ serving/day ( $\geq 16 \mathrm{~g} /$ day) was further estimated, for this study only, by assuming that approximately $70 \%$ of the incremental dietary fiber between the middle and highest WG intake groups was attributable to WG intake, with $3.58 \mathrm{~g}$ of fiber per $16 \mathrm{~g}$ of WG. Sensitivity analyses were completed to assess the degree to which different assumptions for the Albertson et al. (2016) study impacted the overall results [23]. Varying the estimate for the highest WG intake group from 16 to $40 \mathrm{~g} /$ day did not materially alter parameter estimates for the study.

Because of differences in analytical (e.g., statistical, dietary assessment, etc.) methods employed and reporting of multiple analyses over different follow-up periods, some within the same cohorts, it was not possible to conduct a meaningful pooled analysis of data from prospective cohort studies. Therefore, a qualitative assessment of the results was undertaken to evaluate strength, consistency, and dose-response for the associations between baseline WG intake and change in WG intake and change in measures of body weight.

\subsection{Meta-Regression Analysis of WG Intake: RCTs}

The primary outcome of the RCT data meta-analysis was change in body weight $(\mathrm{kg})$, expressed as the standardized mean difference between the exposed group with the highest WG intake reported and the control group. Secondary and sensitivity analyses were conducted to assess the relationship of higher WG versus a control on (1) change in waist circumference (cm), (2) change in body fat percentage, (3) weight change $(\mathrm{kg})$ in a subset of studies that included subjects of both sexes, and (4) weight change $(\mathrm{kg})$ in hypocaloric intervention studies.

Cochrane risk of bias for clinical trials was assessed [25] with nutrition-specific items from a critical appraisal of systematic reviews in the field of nutrition [26]. The methodologic quality of each study was evaluated based on predefined criteria, in accordance with the Agency for Healthcare Research and Quality recommendations for systematic reviews [27]. Study quality for individual domains was determined in duplicate (OMP and HNC), and discrepancies were resolved by consensus in group conference. Preliminary study quality screening included ensuring studies met all the predetermined inclusion and none of the exclusion criteria as well as adequate study length and statistical power for RCTs and the inclusion of relevant cofounding analyses for observational studies. Study quality was assessed in duplicate by two scientists (KCM and OMP) using the Heyland Methodologic Quality Score (MQS) — a tool which rates study methodologic quality on the basis of nine criteria: random assignment, analysis, blinding, patient selection, baseline group comparability, extent of follow-up, treatment protocol, co-interventions, and outcomes [28,29]. Studies are rated between 0 (lowest quality) and 14 (highest quality), and studies with a rating of $\geq 8$ are considered high-quality trials (Table S4).

\subsection{Statistical Analyses}

Descriptive statistics and both unweighted and weighted meta-regression analyses were completed using SPSS Statistics, version 25.0 (IBM, Armonk, NY, USA). Since insufficient data were available for inverse variance weighting for all studies, the weighting scheme used the number of subjects in each group as the weighting factor. Unless otherwise specified, an alpha level of 0.05 was used to define statistical significance.

Pooled analyses were completed using the Meta-analysis with Interactive eXplanations (MIX, version 2.0) program [30]. Within-group changes and standard error (SE) for within-group change were based on reported values obtained from the publication; when these values were not reported, they were calculated from the reported group mean and SE or standard deviation (SD) for the baseline and final values within each group: 


$$
\mathrm{SE}_{\text {Change }}=\left(\mathrm{SE}_{\text {Final }}^{2}-\mathrm{SE}_{\text {Baseline }}^{2}-2 \times \mathrm{r} \times \mathrm{SE}_{\text {Final }} \times \mathrm{SE}_{\text {Baseline }}\right)^{0.5} \text {, }
$$

where $\mathrm{r}$ is the correlation coefficient between baseline and final values (within-group). A value of 0.59 was used for $r$, as suggested in an empirical evaluation of within-group correlations [31]. The SE of the difference in response between groups was calculated as follows

$$
\mathrm{SE}_{\text {Difference }}=\left(\mathrm{SE}^{2} \text { ChangeWG }+\mathrm{SE}^{2} \text { ChangeControl }\right)^{0.5} \text {. }
$$

Values are reported as standardized mean differences between treatment groups with corresponding 95\% confidence intervals (CIs). Pooled estimates with 95\% CIs and $p$-values were calculated from random effects meta-analysis models. For the RCT analyses, between-study heterogeneity was assessed with the $\mathrm{Q}$ and the $I^{2}$ statistics [32].

\section{Results}

A flow diagram summarizing the results of the literature search is shown in Figure 1 for observational studies and Figure 2 for RCTs.

\subsection{Meta-Regression Analysis: Cross-Sectional Studies}

Twelve observational studies-from 11 original publications meeting all the inclusion and none of the exclusion criteria-provided data on WG intake and BMI by WG intake category [3,23,24,33-40]. Of these, nine studies were cross-sectional by design [23,24,33-36,38,39], and the remaining three were designed as prospective cohort studies but provided cross-sectional data at baseline [3,37,40] (Table S5). The definition of WG varied within these studies, ranging from the inclusion of only a specific food, WG bread [3], or WG definition for foods (foods containing $\geq 51 \%$ WG content by weight) [40] to total servings per day as part of the entire diet [23,24,35].

The meta-regression analysis of cross-sectional data from the observational studies indicates a significant, inverse association between WG intake and BMI (Figure 3). When the association is assessed as BMI on g/day of WG intake, the unweighted analysis showed a slope of $-0.0146 \mathrm{~kg} / \mathrm{m}^{2}$ per $\mathrm{g} /$ day of WG intake (95\% confidence interval (CI): $-0.0238,-0.0054 ; \mathrm{r}=-0.406 ; p=0.0034)$, whereas the weighted analysis indicates a similar slope of $-0.0141 \mathrm{~kg} / \mathrm{m}^{2}$ per g/day of WG intake (95\% CI: -0.0207 , $-0.0077 ; \mathrm{r}=-0.526 ; p=0.0001)$.

\subsection{Qualitative Analysis: Prospective Cohort Studies}

A summary of the results from prospective cohort studies is included in Table 1. Six publications were identified that included analyses from four US cohorts of health professionals (Nurses' Health Study (NHS) I and II, Physicians' Health Study (PHS), Health Professionals Follow-up Study (HPFS)) and two European cohorts (Seguimiento Universidad de Navarra (SUN) in Spain and the Northern Sweden Health and Disease Study (NSHD)) [3,37,40-43].

In five of the six prospective studies assessed, aging was shown to be associated with weight gain [37,40-43]; thus, results reported on the level of weight gain attenuation rather than weight loss. All analyses adjusted for a variety of potential confounders, and the fully adjusted analysis was used in the primary assessment of effect for each study. Two studies reported on the association between baseline intake of a specific type of WG food and change in weight during follow-up. The SUN investigators reported that higher WG bread intake was not significantly associated with weight change or incident overweight/obesity in 9267 subjects in a Mediterranean cohort (54\% women) followed for an average of five years [3]. In the PHS of 17,881 US male physicians, increasing intake of WG breakfast cereal was associated with significantly less weight gain at 8 years after adjustment for covariates ( 1.55 vs. $1.13 \mathrm{~kg}$ for extreme categories, $p$ for trend $=0.003)$ [41]. A similar pattern was observed at the longer follow up period of 13 years (2.18 vs. $1.83 \mathrm{~kg}$ for extreme categories, $p$ for trend $=0.08)$, although the dose-response association did not reach the $5 \%$ level of statistical significance. 


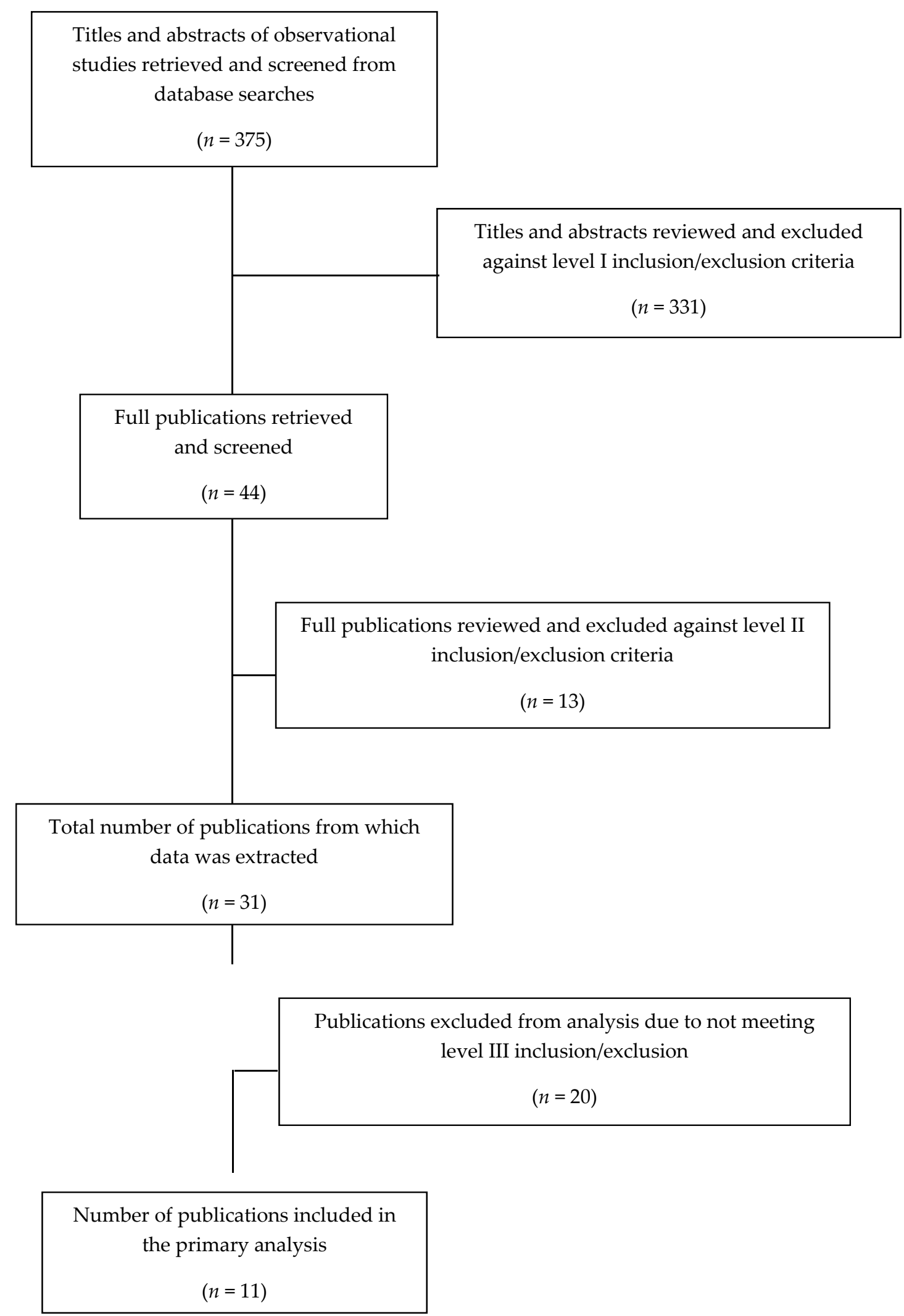

Figure 1. Flow diagram of literature search for observational study analyses inclusion. 


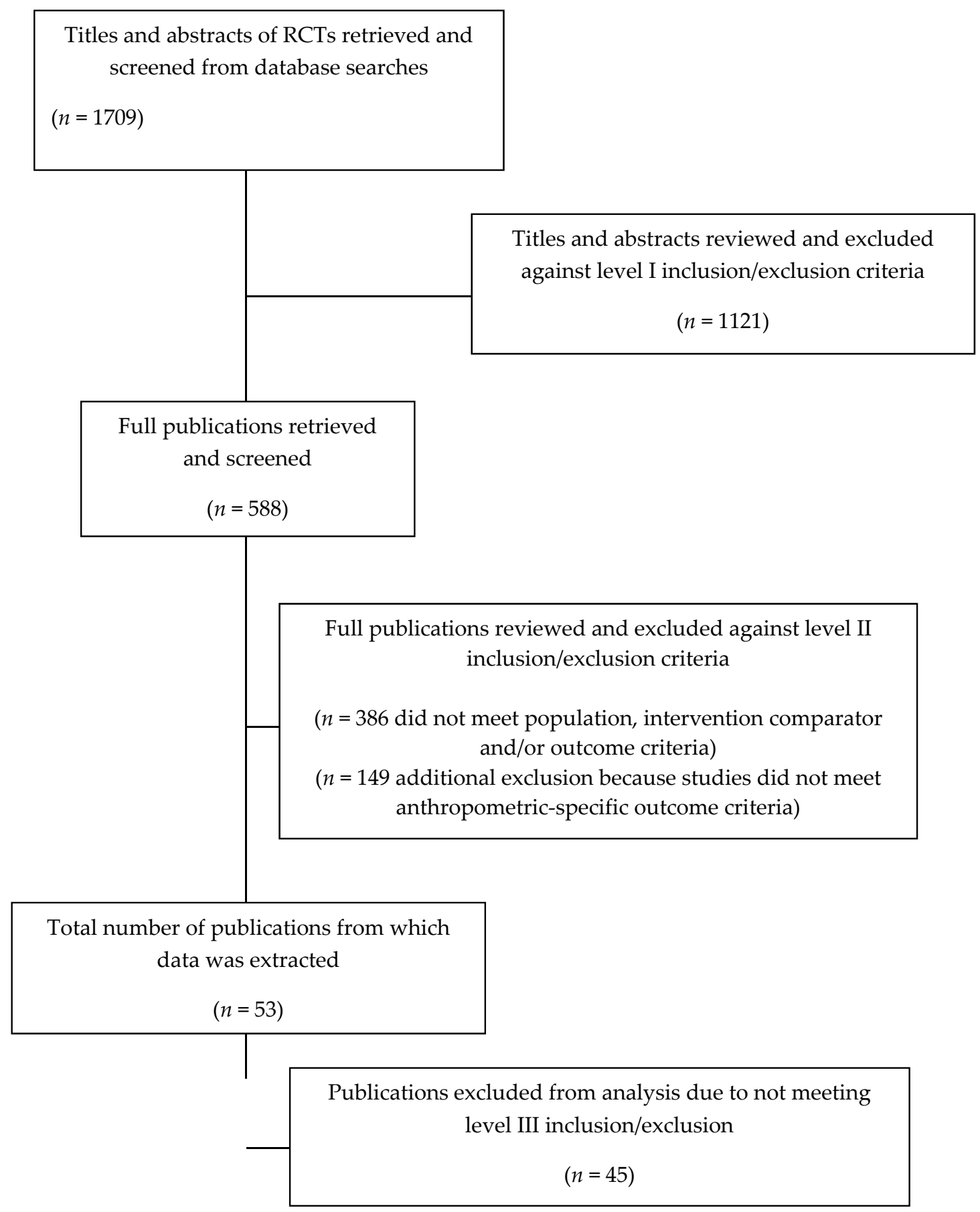

Number of publications included in the primary analysis

$$
(n=8)
$$

Figure 2. Flow diagram of literature search for RCT analyses inclusion. 


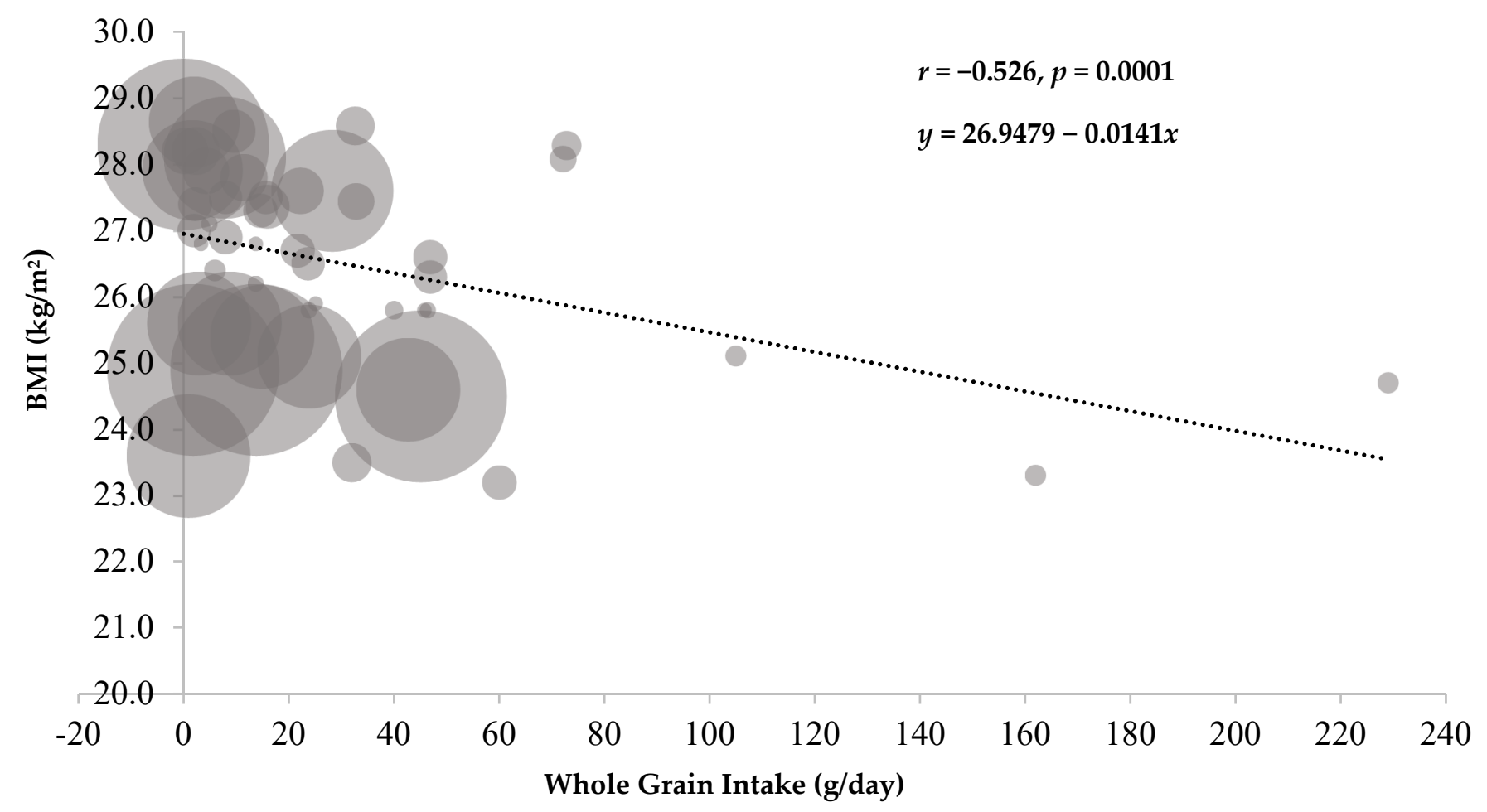

Figure 3. Weighted bubble plot of cross-sectional data from observational studies for the relationship between whole grain intake and body mass index (BMI) ${ }^{1}$.

${ }^{1}$ For the unweighted analysis, the regression equation is $\mathrm{y}=26.9211-0.0146 x ; \mathrm{r}=-0.406(p=0.0034)$. 
Table 1. Outcomes summary of 6 cohort studies assessing the prospective association between WG intake and weight change ${ }^{1}$.

\begin{tabular}{|c|c|c|c|c|c|}
\hline Study Author, Year & Cohort (Country) & Subject Number & Follow-Up (Years) & WG Exposure & Main Weight Outcome \\
\hline $\begin{array}{l}\text { Liu, } \\
2003 \text { [37] }\end{array}$ & $\begin{array}{l}\text { NHS, females } \\
\text { (United States) }\end{array}$ & 74,091 & 12 & $\begin{array}{l}\text { Dark bread, WG cereals, } \\
\text { popcorn, wheat germ, brown } \\
\text { rice, bran, bulgur, kasha, } \\
\text { couscous, etc. }\end{array}$ & $\begin{array}{c}\text { WG intake inversely associated } \\
\text { with weight gain }\end{array}$ \\
\hline $\begin{array}{l}\text { Koh-Banerjee, } \\
2004[40]\end{array}$ & $\begin{array}{l}\text { HPFS, males } \\
\text { (United States) }\end{array}$ & 27,082 & 8 & $\begin{array}{l}\text { WG foods with at least } 51 \% \text { WG } \\
\text { content by weight }\end{array}$ & $\begin{array}{c}\text { WG intake inversely associated } \\
\text { with weight gain }\end{array}$ \\
\hline $\begin{array}{l}\text { Bazzano, } \\
2005[41]\end{array}$ & $\begin{array}{l}\text { PHS, males } \\
\text { (United States) }\end{array}$ & 17,881 & 13 & $\begin{array}{l}\text { WG ready-to-eat } \\
\text { breakfast cereals }\end{array}$ & $\begin{array}{l}\text { WG breakfast cereal intake } \\
\text { inversely linked to weight gain }\end{array}$ \\
\hline $\begin{array}{l}\text { Mozaffarian, } \\
2011[43]\end{array}$ & $\begin{array}{l}\text { NHS, NHS II, HPFS } \\
\text { (collectively males and } \\
\text { females) } \\
\text { (United States) }\end{array}$ & 120,877 & 20 & $\begin{array}{l}\text { Bran, brown rice, cold breakfast } \\
\text { cereal, cooked oatmeal, other } \\
\text { cooked breakfast cereal, dark } \\
\text { bread, and wheat germ }\end{array}$ & $\begin{array}{l}\text { WG intake inversely associated } \\
\text { with the among of weight gain }\end{array}$ \\
\hline $\begin{array}{l}\text { De la Feuente-Arrillaga, } \\
2014[3]\end{array}$ & $\begin{array}{l}\text { SUN Project, males and } \\
\text { females (Spain) }\end{array}$ & 9,267 & 5 & WG bread & $\begin{array}{l}\text { No association of WG bread } \\
\text { intake with weight change }\end{array}$ \\
\hline $\begin{array}{l}\text { Winkvist, [42] } \\
\quad 2017\end{array}$ & $\begin{array}{l}\text { NSHD, males and females } \\
\text { (Sweden) }\end{array}$ & 15,995 & 10 & NR & $\begin{array}{l}\text { WG intake inversely associated } \\
\text { with BMI change in men only }\end{array}$ \\
\hline
\end{tabular}


In two prospective studies that analyzed change in WG intake from baseline in relation to change in weight, Liu (2003) and Koh-Banerjee (2004), reported inverse associations in body weight within the NHS I cohort ( $p$ for trend $=<0.0001$ ) and HPFS cohort ( $p$ for trend $=0.002$ ) $[37,40]$. Specifically, WG intake in the NHS I cohort was associated with less average weight gain (1.07 kg in the highest quintile of WG intake versus $1.58 \mathrm{~kg}$ in the lowest quintile of WG over 2-4 years) [37], and for every $40 \mathrm{~g} /$ day intake of WG from foods within the HPFS cohort, weight gain was lower by $0.49 \mathrm{~kg}$ over an 8-year follow-up [40]. Mozaffarian and colleagues later reported on the pooled data generated from these cohorts and additional data from NHS II and assessed the relationship between lifestyle factors and weight change over follow-up periods up to 20 years $(n=120,877)$ [43]. They observed that within each 4-year period, average weight gain was $1.52 \mathrm{~kg}$ in participants, but in multivariate analyses, each serving per day increase in WG intake was associated with $0.17 \mathrm{~kg}$ (95\% CI 0.22 to $0.22 \mathrm{~kg}, p<0.001)$ less weight gain. Winkvist et al. (2017) reported on 10-year follow-up in a subset of the NSHD cohort, and similar to the results in U.S. cohorts, both men and women gained weight, averaging an increase of $2.5 \mathrm{~kg}$ over the study period [42]. Each $\mathrm{g} / 2000 \mathrm{kcal}$ of WG intake was significantly inversely associated in multivariate analyses with BMI change in men $(n=7641$, beta $\pm \mathrm{SE}=-0.13 \pm 0.03, p<0.001)$, but not in women $(n=8354,-0.02 \pm 0.03, p=0.55)$. Thus, age-related weight gain is the norm in these prospective cohort studies, and generally, higher intake of WG foods was associated with attenuation of weight gain.

\subsection{Meta-Analysis: RCTs}

Data from nine RCTs were extracted from eight publications for the primary analysis and included data from 973 study participants (472 WG intervention, 501 control intervention) [44-51]. Of these, seven were 12-week interventions [44-50] and two studies were 16-week interventions, but from the same publication [51] (Table S4). WG intake ranged from $32 \mathrm{~g} /$ day to $215 \mathrm{~g} /$ day for the WG interventions and from $0 \mathrm{~g} /$ day to $19 \mathrm{~g} /$ day for the studies reporting WG daily intake for the control interventions. Five studies did not report daily WG intake for the control intervention $[44-46,48,49]$. As with the observational data, the definition of WG varied within studies, ranging from the inclusion of only fiber-rich WG breakfast cereals [44] to a diet with only WGs in grain foods [47]. All nine RCTs are considered high-quality trials (Heyland MQS of $\geq 8$ ). The lowest Heyland MQS score was 9 [45,49], and the highest was 13 [46,47]. As shown in Table 2 and Figure 4, a nonsignificant pooled standardized effect size of $-0.049 \mathrm{~kg}(95 \%$ CI $-0.297,0.199, p=0.698)$ in mean difference in weight change was observed for the WG intervention groups compared with controls. The model showed statistically significant heterogeneity $\left(\mathrm{Q}=28.1, p=<0.001, I^{2}=71.5 \%\right)$. There was no indication of publication bias based on Begg's and Egger's test results (data not shown).

Table 2. Random effects meta-analysis model of 9 trials assessing relationship of WG interventions on weight change $(\mathrm{kg})^{1,2}$.

\begin{tabular}{cccccc}
\hline Study Author, Year & Subjects & SMD & $\mathbf{9 5 \% ~ C I ~}$ & $p$-Value & Weight \\
\hline Melanson, 2006 [44] & 91 & 0.134 & $-0.277,0.545$ & 0.524 & $11.35 \%$ \\
Katcher, 2008 [45] & 47 & 0.712 & $0.140,1.284$ & 0.015 & $8.78 \%$ \\
Maki, 2010 [46] & 144 & -0.223 & $-0.550,0.105$ & 0.183 & $12.81 \%$ \\
Kristensen, 2012 [48] & 72 & -0.401 & $-0.863,0.062$ & 0.090 & $10.47 \%$ \\
Chang, 2013 [49] & 34 & -1.158 & $-1.831,-0.484$ & 0.001 & $7.43 \%$ \\
Harris Jackson, 2014 [50] & 50 & -0.267 & $-0.822,0.287$ & 0.345 & $9.03 \%$ \\
Kristensen, 2017 [47] & 169 & 0.000 & $-0.302,0.302$ & 1.000 & $13.25 \%$ \\
Brownlee, 2010 [51] & 185 & 0.312 & $0.023,0.601$ & 0.035 & $13.47 \%$ \\
Brownlee, 2010 [51] & 181 & 0.089 & $-0.204,0.382$ & 0.551 & $13.41 \%$ \\
\hline Pooled & 973 & -0.049 & $0.199,-0.388$ & 0.698 & $100.00 \%$ \\
\hline
\end{tabular}

${ }^{1}$ Studies included in the analysis are reference numbers [44-51]. ${ }^{2}$ Heterogeneity: $\mathrm{Q}=28.1, p=<0.001, I^{2}=71.5 \%$; Abbreviations: CI: confidence interval; SMD: standardized mean difference. 
Melanson, 2006

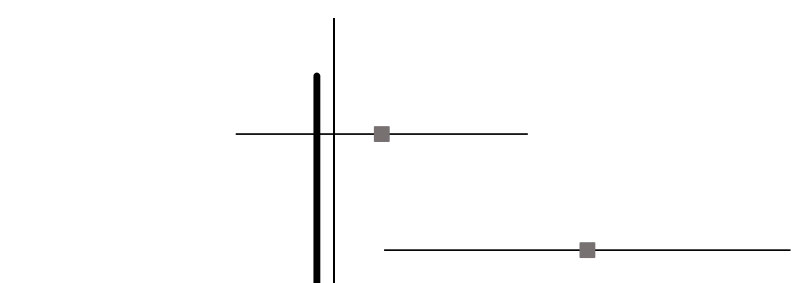

Maki, 2010

Kristensen, 2012

Chang, 2013

Harris Jackson, 2014

Kristensen, 2017

Brownlee, 2010

Brownlee, 2010

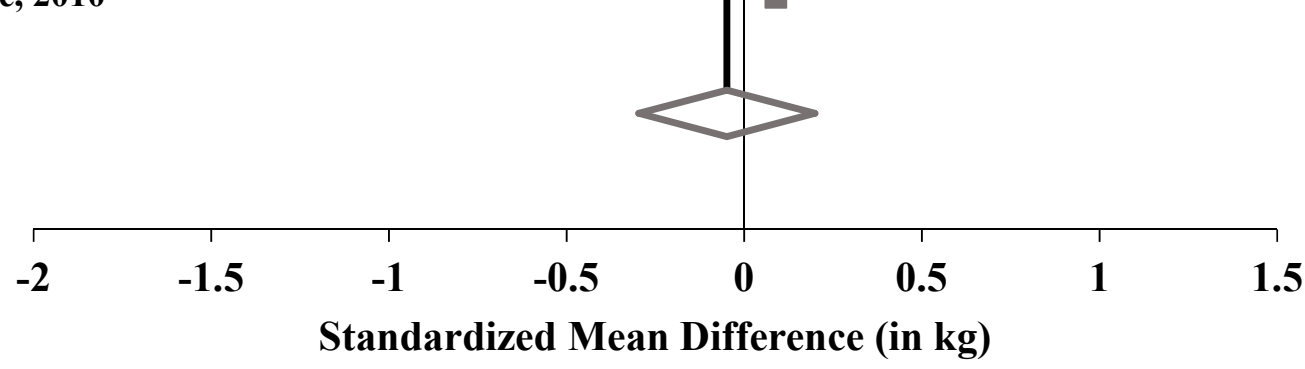

Figure 4. Synthesis forest plot of included studies (values to the left of the line indicate net weight loss for the whole grain intervention).

Secondary analyses were conducted to assess the effect of WG interventions on change in waist circumference, change in body fat percentage, as well as change in weight in the subsets of RCTs that included both male and female subjects, and in which the dietary interventions were part of a hypocaloric diet (Table 3). The results indicate no significant effect of WG interventions on weight status or other measures for any of the secondary analyses conducted. 
Table 3. Secondary meta-analyses of RCTs assessing the outcome of WG intake (g/day) on waist circumference, body fat percentage, or weight change $(\mathrm{kg})^{1,2}$.

\begin{tabular}{|c|c|c|c|c|c|}
\hline $\begin{array}{l}\text { Secondary } \\
\text { Analysis }\end{array}$ & Included Studies & Subjects & SMD & $95 \%$ CI & $p$-Value \\
\hline $\begin{array}{c}\text { Waist } \\
\text { Circumference }\end{array}$ & $\begin{array}{c}\text { Katcher, } 2008 \text { [45] } \\
\text { Maki, } 2010 \text { [46] } \\
\text { Kristensen, } 2012 \text { [48] } \\
\text { Harris Jackson, } 2014 \text { [50] } \\
\text { Kristensen, 2017 [47] }\end{array}$ & 482 & 0.276 & $-0.436,0.989$ & 0.447 \\
\hline $\begin{array}{l}\text { Body Fat } \\
\text { Percentage }\end{array}$ & $\begin{array}{c}\text { Katcher, } 2008 \text { [45] } \\
\text { Chang, } 2013 \text { [49] } \\
\text { Harris Jackson, } 2014 \text { [50] } \\
\text { Kristensen, } 2017 \text { [47] } \\
\text { Brownlee, } 2010 \text { [51] } \\
\text { Brownlee, } 2010 \text { [51] }\end{array}$ & 666 & 0.042 & $-0.573,0.656$ & 0.895 \\
\hline $\begin{array}{c}\text { Mixed } \\
\text { Population }\end{array}$ & $\begin{array}{c}\text { Melanson, } 2006 \text { [44] } \\
\text { Katcher, } 2008 \text { [45] } \\
\text { Maki, 2010 [46] } \\
\text { Chang, 2013 [49] } \\
\text { Harris Jackson, } 2014 \text { [50] } \\
\text { Brownlee, } 2010 \text { [51] } \\
\text { Brownlee, } 2010 \text { [51] }\end{array}$ & 732 & -0.016 & $-0.329,0.297$ & 0.921 \\
\hline $\begin{array}{c}\text { Hypocaloric } \\
\text { Diet }\end{array}$ & $\begin{array}{c}\text { Melanson, } 2006 \text { [44] } \\
\text { Katcher, 2008 [45] } \\
\text { Maki, 2010 [46] } \\
\text { Kristensen, 2012 [48] } \\
\text { Harris Jackson, 2014 [50] } \\
\text { Kristensen, 2017 [47] }\end{array}$ & 573 & -0.031 & $-0.291,0.229$ & 0.814 \\
\hline
\end{tabular}

${ }^{1}$ Studies included in the secondary analyses [44-51]. ${ }^{2}$ Weight change was the analysis outcome for the secondary analyses of RCTs employing a mixed (male and female subjects) population or RCTs with a study design which included a hypocaloric diet as part of the interventions. Abbreviations: CI: confidence interval; SMD: standardized mean difference; RCT: randomized controlled trial; WG: whole grains.

\section{Discussion}

The results of the meta-regression analysis of the cross-sectional evidence show a significant inverse relationship between WG intake and BMI. Findings from prospective cohort studies support this relationship, with baseline WG intake and change in WG intake generally showing inverse associations with weight change during follow-up periods of four to 20 years, particularly in the studies with larger numbers of subjects. These relationships remained statistically significant in most cases after adjustment for a variety of covariates and potential confounders. These results are consistent with those from a recent meta-analysis of prospective studies assessing the association of food group intake and risk for overweight/obesity and weight gain [52]. In that analysis, five studies were included in the meta-analysis on incident overweight and/or obesity, which yielded a summary relative risk of 0.85 (95\% CI: 0.79-0.91) for high vs. low WG product intake $\left(I^{2}=0 \%\right)$. Three studies were included in that paper's final dose-response meta-analysis for the WG food group [37,41,53], where an inverse relationship (relative risk for overweight/obesity $0.93,95 \%$ CI $0.89-0.96$ ) per $30 \mathrm{~g} /$ day higher intake of WG products was observed. Three studies were included in the analysis of WG product consumption and the risk for weight gain, with weight gain defined as $>2 \mathrm{~kg}$ during a mean period of 4 years, $\geq 10 \mathrm{~kg}$ during 13 years, or $\geq 25 \mathrm{~kg}$ during an average period of 12 years. The summary relative risk $(95 \% \mathrm{CI})$ for weight gain was 0.83 (0.70 to 0.97$)$, with $I^{2}=16 \%$ in the high compared with low intake analysis, and 0.91 (0.82 to 1.02), $I^{2}=69 \%$, for each increase of $30 \mathrm{~g}$ of whole grain products/day.

Results from the primary and secondary meta-analyses of RCT evidence in the present investigation failed to show a significant effect of higher WG intake on body weight, consistent with findings from some prior reviews [6,9], but not with those from another recent meta-analysis [54]. Reynolds et al. 
(2019) reported on the results of meta-analysis of 11 RCTs (919 adult participants) assessing the effect of WG on body weight and concluded that WG intake has a significant (mean difference: $-0.62 \mathrm{~kg}$, $(95 \% \mathrm{CI}$ -1.19 to -0.05$)$ ) association with change in body weight [54]. Some differences exist between the present analyses compared to that of Reynolds et al. (2019). Of the nine studies included in the present meta-analysis and the 11 included in the Reynolds et al. (2019) analysis, only Brownlee et al. (2010) and Chang et al. (2013) were included in both [49,51]. The remaining nine RCTs included by Reynolds et al. (2019) did not meet our inclusion/exclusion criterion of a 12-wk minimum intervention period [55-58], did not provide sufficient information to quantify the amount of WG in the intervention [59,60], did not provide WG in food (e.g., the intervention was provided as a high-fiber fraction of WG) [61], or instructed subjects to maintain stable body weight [59,62]. Reynolds et al. (2019) excluded trials that employed a hypocaloric (weight loss) diet as part of the intervention, whereas they were included in the present analysis.

One possible explanation for the lack of apparent effect of WG intake on body weight in RCTs in the present analysis may be that WG, per se, may not be causally related to body weight or related anthropometric variables. WG intake could be a marker for lifestyle or habits conducive to lower body weight, and the relationships in observational studies could be attributable to residual confounding. For example, WG intake may correlate with healthful lifestyle factors such as healthy dietary patterns, mindful eating behaviors, greater physical activity levels, and/or longer sleep duration [63-66]. This phenomenon has been observed in children where oatmeal intake at the breakfast meal was a marker for better overall diet quality and nutrient intake versus other typical breakfast foods (e.g., eggs; ready-to-eat, high-sugar cereals; and pancakes/waffles) [67]. In U.S. adults, WG intake is positively associated with higher diet quality and higher intakes of most micronutrients, dietary fiber, polyunsaturated fatty acids, and total energy, and inversely associated with intake of total and added sugars, monounsaturated fatty acids, saturated fatty acids, and cholesterol [68]. In the United Kingdom, WG intake is associated with higher intakes of magnesium, fiber, and iron, and lower intake of sodium [69]. Therefore, it is possible that the association of WG intake with lower weight status is due to residual confounding and is noncausal [70]. The potential for bias and other types of confounding is an inherent limitation of observational studies, and, ideally, such associations should be confirmed with evidence from well-controlled RCTs [70].

Another possible explanation for the differing relationships in the observational and RCT analyses is that the RCTs may not have been adequate to assess longer-term effects of WG intake on body weight and composition. There are several biologically plausible mechanisms through which higher WG intake could affect energy balance and body composition, including effects on appetite and energy expenditure [7,71]. For example, in a 3-week crossover, blind intervention study assessing the effect of daily breakfast intake of WG rye porridge versus refined flour wheat bread, increases in postprandial subjective ratings of satiety were observed with the rye porridge in healthy adults [71]. In addition, there are some potentially relevant mechanisms that may be mediated by effects of WGs and components, such as fermentable fibers, on gut microbiota [14,72-74]. For example, consuming an evening meal containing WG rye flour bread, versus the refined flour, wheat-based bread meal, reduced circulating free fatty acids and increased breath hydrogen, two indicators of increased gut fermentation, in healthy adults [74]. These influences may be too small to have a meaningful impact on the short-term and may require longer periods to manifest. The longest follow-up period in the RCTs assessed was 16 weeks and only two of the nine RCT comparisons were from interventions longer than 12 weeks [51].

An additional consideration is variation in the definitions of WG foods used in both RCTs and observational studies [22]. In 2006, the United States Food and Drug Administration adopted a WG definition that includes intact, ground, cracked, or flaked fruit of grains whose principal components (the starchy endosperm, germ, and bran) are present in the same relative proportions as in the intact grain [22]. Prior to that, some studies included bran and other high dietary fiber foods in their definitions of WG [75]. Since five of the 12 studies included in the observational data for this study are 
from 2006 or earlier, reported levels of WG intake in those studies potentially include foods/ingredients that are no longer defined as WG. In addition, an analysis of WG intervention study designs found that $73 \%$ of WG intervention studies did not specify a definition for the WG product or food, and only $55 \%$ of longer-term WG intervention trials reported the amount (as grams or servings) of WG used [22]. With respect to variation in WG exposure within these RCTs, WG-containing foods vary in the quantity of WG within a food or product. A specific threshold of WG intake, or one or more components, may be needed to achieve some physiological effects; for example, thresholds of intake and quality are required to yield adequate viscosity in the stomach with oat intake to affect postprandial glycemia [76]. Furthermore, variations may exist with respect to the type of dietary fiber and other potentially bioactive compounds. For instance, both oats and barley are rich in $\beta$-glucans [77], but the major phenolic antioxidants in oats are $p$-hydroxybenzoic acid and vanillic acid, while barley has higher levels of ferulic acid, $p$-coumaric acid, and sinapic acid [77,78].

Lastly, although no significant effects of WGs were observed in RCTs on body composition, the analysis included relatively few studies within which there was marked heterogeneity of results, and results from some trials suggest that body composition and/or body fat distribution may be influenced by WG intake $[7,45]$. Thus, research with longer intervention periods is needed to assess parameters such as adiposity and waist circumference. Additional RCTs are also needed to assess possible influences of WG intake on the determinants of energy balance (appetite and energy expenditure). Since different WG types likely exert varying physiological effects, RCTs assessing the influences of specific WG types on weight status and related anthropometrics are needed. Additionally, well-controlled RCTs with a clear and standardized definition as to what constitutes a WG food (e.g., $\geq 51 \%$ WG ingredient by weight, only $100 \%$ WG food, etc.) are needed to reduce heterogeneity, and exploration of dose-response also warrant further investigation.

\section{Conclusions}

In summary, cross-sectional and prospective data from observational studies suggest an inverse relationship between WG intake and BMI, as well as change in body weight over time. Data from RCTs of at least 12 weeks and up to 16 weeks in duration with WG interventions did not demonstrate significant pooled differences between higher WG and control groups for measures of body weight and related variables such as adiposity and waist circumference. Taken together, the results of these analyses are consistent with dietary recommendations to emphasize intake of WG as part of a healthful eating pattern, although additional research is needed to clarify the potential role of WG food intake in body weight regulation [1].

Supplementary Materials: The following are available online at http:/www.mdpi.com/2072-6643/11/6/1245/s1, Table S1: Search terms used to identify relevant observational and RCT publications for the meta-regression analyses of WG, Table S2: Inclusion and exclusion criteria for observational studies, Table S3: Inclusion and exclusion criteria for randomized controlled trials, Table S4: Summary of the nine trials included in the meta-analysis of data obtained from RCTs assessing the effect of WG intake (g/day) on body weight $(\mathrm{kg})$, Table S5: Summary of the data obtained from the 12 observational studies included in the meta-regression analysis assessing the association between WG intake (g/day) and weight status $\left(\mathrm{BMI}, \mathrm{kg} / \mathrm{m}^{2}\right)$,

Author Contributions: K.C.M., O.M.P., and K.K. designed the study. O.M.P., C.M.S., K.A.L., H.N.C., and N.M.M. collected data. K.C.M. and M.B. conducted statistical analyses. K.C.M., O.M.P., K.K., and N.M.M. interpreted the data. K.C.M., O.M.P. and N.M.M. drafted the manuscript. All authors provided scientific commentary during manuscript drafting, and all authors reviewed and approved the final manuscript.

Funding: This study was funded by General Mills, Inc., and the funding sponsor provided comment on study design, data collection, and results interpretation. However, the final decision for all aspects of study conduct and manuscript content were those of the authors alone. KCM and OMP are employees of Midwest Biomedical Research, which has received funding for other work from the Kellogg Company (Battle Creek, MI).

Acknowledgments: We gratefully acknowledge the nutrition scientists Marissa McCormick and Kevin Miller from General Mills Inc. for thoughtful discussion and scientific review of the manuscript. This study was funded by General Mills, Inc. (Minneapolis, MN). 
Conflicts of Interest: KK is an employee of General Mills, Inc., and all authors received research funding from General Mills, Inc. (Minneapolis, MN).

$\begin{array}{ll}\text { Abbreviations } \\ \text { BMI } & \text { body mass index } \\ \text { CI } & \text { confidence interval } \\ \text { HPFS } & \text { Health Professionals Follow-up Study } \\ \text { MD } & \text { mean difference } \\ \text { NHS } & \text { Nurses' Health Study } \\ \text { NSHD } & \text { Northern Sweden Health and Disease Study } \\ \text { PHS } & \text { Physicians' Health Study } \\ \text { RCT } & \text { randomized controlled trial } \\ \text { RG } & \text { refined grain } \\ \text { SD } & \text { standard deviation } \\ \text { SE } & \text { standard error } \\ \text { SEM } & \text { standard error of the mean } \\ \text { SMD } & \text { standardized mean difference } \\ \text { SUN } & \text { Seguimiento Universidad de Navarra } \\ \text { WG } & \text { whole grain }\end{array}$

\section{References}

1. U.S. Department of Health and Human Services and U.S. Department of Agriculture. 2015-2020 Dietary Guidelines for Americans. Available online: http://health.gov/dietaryguidelines/2015/guidelines/ (accessed on 14 November 2018).

2. Van der Kamp, J.W.; Poutanen, K.; Seal, C.J.; Richardson, D.P. The HEALTHGRAIN definition of “whole grain”. Food Nutr. Res. 2014, 58. [CrossRef]

3. De la Fuente-Arrillaga, C.; Martinez-Gonzalez, M.A.; Zazpe, I.; Vazquez-Ruiz, Z.; Benito-Corchon, S.; Bes-Rastrollo, M. Glycemic load, glycemic index, bread and incidence of overweight/obesity in a Mediterranean cohort: The SUN project. BMC Public Health 2014, 14, 1091. [CrossRef] [PubMed]

4. Reicks, M.; Jonnalagadda, S.; Albertson, A.M.; Joshi, N. Total dietary fiber intakes in the US population are related to whole grain consumption: Results from the National Health and Nutrition Examination Survey 2009 to 2010. Nutr. Res. 2014, 34, 226-234. [CrossRef]

5. Mozaffarian, D. Dietary and Policy Priorities for Cardiovascular Disease, Diabetes, and Obesity: A Comprehensive Review. Circulation 2016, 133, 187-225. [CrossRef]

6. Giacco, R.; Della Pepa, G.; Luongo, D.; Riccardi, G. Whole grain intake in relation to body weight: From epidemiological evidence to clinical trials. Nutr. Metab. Cardiovasc. Dis. 2011, 21, 901-908. [CrossRef]

7. Karl, J.P.; Saltzman, E. The role of whole grains in body weight regulation. Adv. Nutr. 2012, 3, 697-707. [CrossRef] [PubMed]

8. Thielecke, F.; Jonnalagadda, S.S. Can whole grain help in weight management? J. Clin. Gastroenterol. 2014, 48, S70-S77. [CrossRef]

9. Pol, K.; Christensen, R.; Bartels, E.M.; Raben, A.; Tetens, I.; Kristensen, M. Whole grain and body weight changes in apparently healthy adults: A systematic review and meta-analysis of randomized controlled studies. Am. J. Clin. Nutr. 2013, 98, 872-884. [CrossRef] [PubMed]

10. US Department of Agriculture (USDA), Agricultural Research Service, Nutrient Data Laboratory. USDA National Nutrient Database for Standard Reference, Legacy. Available online: http:/www.ars.usda.gov/ nutrientdata (accessed on 24 September 2018).

11. Kranz, S.; Dodd, K.W.; Juan, W.Y.; Johnson, L.K.; Jahns, L. Whole Grains Contribute Only a Small Proportion of Dietary Fiber to the U.S. Diet. Nutrients 2017, 9, 153. [CrossRef]

12. Center for Nutrition Policy and Promotion; U.S. Department of Agriculture Website. Nutrient Content of the U.S. Food Supply, 1909-2010. Fiber Content from Major Food Groups. Calculated by USDA/Center for Nutrition Policy and Promotion. Available online: https://www.cnpp.usda.gov/USFoodSupply-1909--2010 (accessed on 5 December 2018). 
13. Office of Nutrition and Food Labeling. The Declaration of Certain Isolated or Synthetic Non-Digestible Carbohydrates as Dietary Fiber on Nutrition and Supplement Facts Labels: Guidance for Industry; Food and Drug Administration: College Park, MD, USA, 2018.

14. Office of Nutrition and Food Labeling. Review of the Scientific Evidence on the Physiological Effects of Certain Non-Digestible Carbohydrates; Food and Drug Administration: College Park, MD, USA, 2018.

15. Jovanovski, E.; Khayyat, R.; Zurbau, A.; Komishon, A.; Mazhar, N.; Sievenpiper, J.L.; Blanco Mejia, S.; Ho, H.V.T.; Li, D.; Jenkins, A.L.; et al. Should Viscous Fiber Supplements Be Considered in Diabetes Control? Results from a Systematic Review and Meta-analysis of Randomized Controlled Trials. Diabetes Care 2019. [CrossRef] [PubMed]

16. Stewart, M.L.; Wilcox, M.L.; Bell, M.; Buggia, M.A.; Maki, K.C. Type-4 Resistant Starch in Substitution for Available Carbohydrate Reduces Postprandial Glycemic Response and Hunger in Acute, Randomized, Double-Blind, Controlled Study. Nutrients 2018, 10, 129. [CrossRef]

17. Rebello, C.J.; O’Neil, C.E.; Greenway, F.L. Dietary fiber and satiety: The effects of oats on satiety. Nutr. Rev. 2016, 74, 131-147. [CrossRef]

18. Hu, Y.; Song, Y.; Franke, A.A.; Hu, F.B.; van Dam, R.M.; Sun, Q. A Prospective Investigation of the Association Between Urinary Excretion of Dietary Lignan Metabolites and Weight Change in US Women. Am. J. Epidemiol. 2015, 182, 503-511. [CrossRef]

19. Xu, C.; Liu, Q.; Zhang, Q.; Gu, A.; Jiang, Z.Y. Urinary enterolactone is associated with obesity and metabolic alteration in men in the US National Health and Nutrition Examination Survey 2001-10. Br. J. Nutr. 2015, 113, 683-690. [CrossRef]

20. Rietjens, I.M.C.M.; Louisse, J.; Beekmann, K. The potential health effects of dietary phytoestrogens. Br. J. Pharmacol. 2017, 174, 1263-1280. [CrossRef]

21. Moher, D.; Liberati, A.; Tetzlaff, J.; Altman, D.G. Preferred reporting items for systematic reviews and meta-analyses: The PRISMA statement. PLoS Med. 2009, 6, e1000097. [CrossRef]

22. Sawicki, C.M.; Livingston, K.A.; Ross, A.B.; Jacques, P.F.; Koecher, K.; McKeown, N.M. Evaluating Whole Grain Intervention Study Designs and Reporting Practices Using Evidence Mapping Methodology. Nutrients 2018, 10, 1052. [CrossRef]

23. Albertson, A.M.; Reicks, M.; Joshi, N.; Gugger, C.K. Whole grain consumption trends and associations with body weight measures in the United States: Results from the cross sectional National Health and Nutrition Examination Survey 2001-2012. Nutr. J. 2016, 15, 8. [CrossRef]

24. O'Neil, C.E.; Zanovec, M.; Cho, S.S.; Nicklas, T.A. Whole grain and fiber consumption are associated with lower body weight measures in US adults: National Health and Nutrition Examination Survey 1999-2004. Nutr. Res. 2010, 30, 815-822. [CrossRef]

25. Higgins, J.P.; Altman, D.G.; Gotzsche, P.C.; Juni, P.; Moher, D.; Oxman, A.D.; Savovic, J.; Schulz, K.F.; Weeks, L.; Sterne, J.A. The Cochrane Collaboration's tool for assessing risk of bias in randomised trials. BMJ 2011, 343, d5928. [CrossRef]

26. Lichtenstein, A.H.; Yetley, E.A.; Lau, J. Application of systematic review methodology to the field of nutrition. J. Nutr. 2008, 138, 2297-2306. [CrossRef]

27. Der Simonian, R.; Laird, N. Meta-analysis in clinical trials. Control Clin. Trials 1986, 7, 177-188. [CrossRef]

28. Heyland, D.K.; Novak, F.; Drover, J.W.; Jain, M.; Su, X.; Suchner, U. Should immunonutrition become routine in critically ill patients? A systematic review of the evidence. JAMA 2001, 286, 944-953. [CrossRef]

29. Thompson, S.V.; Hannon, B.A.; An, R.; Holscher, H.D. Effects of isolated soluble fiber supplementation on body weight, glycemia, and insulinemia in adults with overweight and obesity: A systematic review and meta-analysis of randomized controlled trials. Am. J. Clin. Nutr. 2017, 106, 1514-1528. [CrossRef]

30. Bax, L. MIX 2.0_Professional software for meta-analysis in Excel. Version 2.015. BiostatXL. Available online: https://www.meta-analysis-made-easy.com (accessed on 5 December 2018).

31. Balk, E.M.; Earley, A.; Patel, K.; Trikalinos, T.A.; Dahabreh, I.J. Empirical Assessment of Within-Arm Correlation Imputation in Trials of Continuous Outcomes; Methods Research Report Prepared by the Tufts Evidence-based Practice Center under Contract No. 290-2007-10055-I, AHRQ Publication No. 12(13)-EHC141-EF; Agency for Healthcare Research and Quality: Rockville, MD, USA, 2012.

32. Higgins, J.P.; Thompson, S.G. Quantifying heterogeneity in a meta-analysis. Stat. Med. 2002, 21, 1539-1558. [CrossRef] 
33. Sahyoun, N.R.; Jacques, P.F.; Zhang, X.L.; Juan, W.; McKeown, N.M. Whole-grain intake is inversely associated with the metabolic syndrome and mortality in older adults. Am. J. Clin. Nutr. 2006, 83, 124-131. [CrossRef]

34. McKeown, N.M.; Meigs, J.B.; Liu, S.; Wilson, P.W.; Jacques, P.F. Whole-grain intake is favorably associated with metabolic risk factors for type 2 diabetes and cardiovascular disease in the Framingham Offspring Study. Am. J. Clin. Nutr. 2002, 76, 390-398. [CrossRef]

35. McKeown, N.M.; Troy, L.M.; Jacques, P.F.; Hoffmann, U.; O’Donnell, C.J.; Fox, C.S. Whole- and refined-grain intakes are differentially associated with abdominal visceral and subcutaneous adiposity in healthy adults: The Framingham Heart Study. Am. J. Clin. Nutr. 2010, 92, 1165-1171. [CrossRef]

36. McKeown, N.M.; Yoshida, M.; Shea, M.K.; Jacques, P.F.; Lichtenstein, A.H.; Rogers, G.; Booth, S.L.; Saltzman, E. Whole-grain intake and cereal fiber are associated with lower abdominal adiposity in older adults. J. Nutr. 2009, 139, 1950-1955. [CrossRef]

37. Liu, S.; Willett, W.C.; Manson, J.E.; Hu, F.B.; Rosner, B.; Colditz, G. Relation between changes in intakes of dietary fiber and grain products and changes in weight and development of obesity among middle-aged women. Am. J. Clin. Nutr. 2003, 78, 920-927. [CrossRef]

38. Lutsey, P.L.; Jacobs, D.R., Jr.; Kori, S.; Mayer-Davis, E.; Shea, S.; Steffen, L.M.; Szklo, M.; Tracy, R. Whole grain intake and its cross-sectional association with obesity, insulin resistance, inflammation, diabetes and subclinical CVD: The MESA Study. Br. J. Nutr. 2007, 98, 397-405. [CrossRef]

39. Esmaillzadeh, A.; Mirmiran, P.; Azizi, F. Whole-grain consumption and the metabolic syndrome: A favorable association in Tehranian adults. Eur. J. Clin. Nutr. 2005, 59, 353-362. [CrossRef]

40. Koh-Banerjee, P.; Franz, M.; Sampson, L.; Liu, S.; Jacobs, J.D.R.; Spiegelman, D.; Willett, W.; Rimm, E. Changes in whole-grain, bran, and cereal fiber consumption in relation to 8-y weight gain among men. Am. J. Clin. Nutr. 2004, 80, 1237-1245. [CrossRef]

41. Bazzano, L.A.; Song, Y.; Bubes, V.; Good, C.K.; Manson, J.E.; Liu, S. Dietary intake of whole and refined grain breakfast cereals and weight gain in men. Obes. Res. 2005, 13, 1952-1960. [CrossRef]

42. Winkvist, A.; Klingberg, S.; Nilsson, L.M.; Wennberg, M.; Renstrom, F.; Hallmans, G.; Boman, K.; Johansson, I. Longitudinal 10-year changes in dietary intake and associations with cardio-metabolic risk factors in the Northern Sweden Health and Disease Study. Nutr. J. 2017, 16, 20. [CrossRef]

43. Mozaffarian, D.; Hao, T.; Rimm, E.B.; Willett, W.C.; Hu, F.B. Changes in diet and lifestyle and long-term weight gain in women and men. N. Engl. J. Med. 2011, 364, 2392-2404. [CrossRef]

44. Melanson, K.J.; Angelopoulos, T.J.; Nguyen, V.T.; Martini, M.; Zukley, L.; Lowndes, J.; Dube, T.J.; Fiutem, J.J.; Yount, B.W.; Rippe, J.M. Consumption of whole-grain cereals during weight loss: Effects on dietary quality, dietary fiber, magnesium, vitamin B-6, and obesity. J. Am. Diet. Assoc. 2006, 106, 1380-1388. [CrossRef]

45. Katcher, H.I.; Legro, R.S.; Kunselman, A.R.; Gillies, P.J.; Demers, L.M.; Bagshaw, D.M.; Kris-Etherton, P.M. The effects of a whole grain-enriched hypocaloric diet on cardiovascular disease risk factors in men and women with metabolic syndrome. Am. J. Clin. Nutr. 2008, 87, 79-90. [CrossRef]

46. Maki, K.C.; Beiseigel, J.M.; Jonnalagadda, S.S.; Gugger, C.K.; Reeves, M.S.; Farmer, M.V.; Kaden, V.N.; Rains, T.M. Whole-grain ready-to-eat oat cereal, as part of a dietary program for weight loss, reduces low-density lipoprotein cholesterol in adults with overweight and obesity more than a dietary program including low-fiber control foods. J. Am. Diet. Assoc. 2010, 110, 205-214. [CrossRef]

47. Kristensen, M.; Pelletier, X.; Ross, A.B.; Thielecke, F. A High Rate of Non-Compliance Confounds the Study of Whole Grains and Weight Maintenance in a Randomised Intervention Trial-The Case for Greater Use of Dietary Biomarkers in Nutrition Intervention Studies. Nutrients 2017, 9, 55. [CrossRef]

48. Kristensen, M.; Toubro, S.; Jensen, M.G.; Ross, A.B.; Riboldi, G.; Petronio, M.; Bugel, S.; Tetens, I.; Astrup, A. Whole grain compared with refined wheat decreases the percentage of body fat following a 12-week, energy-restricted dietary intervention in postmenopausal women. J. Nutr. 2012, 142, 710-716. [CrossRef]

49. Chang, H.C.; Huang, C.N.; Yeh, D.M.; Wang, S.J.; Peng, C.H.; Wang, C.J. Oat prevents obesity and abdominal fat distribution, and improves liver function in humans. Plant Foods Hum. Nutr. 2013, 68, 18-23. [CrossRef]

50. Harris Jackson, K.; West, S.G.; Vanden Heuvel, J.P.; Jonnalagadda, S.S.; Ross, A.B.; Hill, A.M.; Grieger, J.A.; Lemieux, S.K.; Kris-Etherton, P.M. Effects of whole and refined grains in a weight-loss diet on markers of metabolic syndrome in individuals with increased waist circumference: A randomized controlled-feeding trial. Am. J. Clin. Nutr. 2014, 100, 577-586. [CrossRef] 
51. Brownlee, I.A.; Moore, C.; Chatfield, M.; Richardson, D.P.; Ashby, P.; Kuznesof, S.A.; Jebb, S.A.; Seal, C.J. Markers of cardiovascular risk are not changed by increased whole-grain intake: The WHOLEheart study, a randomised, controlled dietary intervention. Br. J. Nutr. 2010, 104, 125-134. [CrossRef]

52. Schlesinger, S.; Neuenschwander, M.; Schwedhelm, C.; Hoffmann, G.; Bechthold, A.; Boeing, H.; Schwingshackl, L. Food Groups and Risk of Overweight, Obesity, and Weight Gain: A Systematic Review and Dose-Response Meta-Analysis of Prospective Studies. Adv. Nutr. 2019, 10, 205-218. [CrossRef]

53. Bautista-Castano, I.; Sanchez-Villegas, A.; Estruch, R.; Martinez-Gonzalez, M.A.; Corella, D.; Salas-Salvado, J.; Covas, M.I.; Schroder, H.; Alvarez-Perez, J.; Quilez, J.; et al. Changes in bread consumption and 4-year changes in adiposity in Spanish subjects at high cardiovascular risk. Br. J. Nutr. 2013, 110, 337-346. [CrossRef]

54. Reynolds, A.; Mann, J.; Cummings, J.; Winter, N.; Mete, E.; Te Morenga, L. Carbohydrate quality and human health: A series of systematic reviews and meta-analyses. Lancet 2019, 393, 434-445. [CrossRef]

55. Ampatzoglou, A.; Atwal, K.K.; Maidens, C.M.; Williams, C.L.; Ross, A.B.; Thielecke, F.; Jonnalagadda, S.S.; Kennedy, O.B.; Yaqoob, P. Increased whole grain consumption does not affect blood biochemistry, body composition, or gut microbiology in healthy, low-habitual whole grain consumers. J. Nutr. 2015, 145, 215-221. [CrossRef]

56. Lappi, J.; Mykkanen, H.; Bach Knudsen, K.E.; Kirjavainen, P.; Katina, K.; Pihlajamaki, J.; Poutanen, K.; Kolehmainen, M. Postprandial glucose metabolism and SCFA after consuming wholegrain rye bread and wheat bread enriched with bioprocessed rye bran in individuals with mild gastrointestinal symptoms. Nutr. J. 2014, 13, 104. [CrossRef]

57. Leinonen, K.; Liukkonen, K.; Poutanen, K.; Uusitupa, M.; Mykkanen, H. Rye bread decreases postprandial insulin response but does not alter glucose response in healthy Finnish subjects. Eur. J. Clin. Nutr. 1999, 53, 262-267. [CrossRef]

58. Tucker, A.J.; Mackay, K.A.; Robinson, L.E.; Graham, T.E.; Bakovic, M.; Duncan, A.M. The effect of whole grain wheat sourdough bread consumption on serum lipids in healthy normoglycemic/normoinsulinemic and hyperglycemic/hyperinsulinemic adults depends on presence of the APOE E3/E3 genotype: A randomized controlled trial. Nutr. Metab. 2010, 7, 37. [CrossRef]

59. Giacco, R.; Lappi, J.; Costabile, G.; Kolehmainen, M.; Schwab, U.; Landberg, R.; Uusitupa, M.; Poutanen, K.; Pacini, G.; Rivellese, A.A.; et al. Effects of rye and whole wheat versus refined cereal foods on metabolic risk factors: A randomised controlled two-centre intervention study. Clin. Nutr. 2013, 32, 941-949. [CrossRef]

60. Bui, T.N.; Le, T.H.; Nguyen do, H.; Tran, Q.B.; Nguyen, T.L.; Le, D.T.; Nguyen do, V.A.; Vu, A.L.; Aoto, H.; Okuhara, Y.; et al. Pre-germinated brown rice reduced both blood glucose concentration and body weight in Vietnamese women with impaired glucose tolerance. J. Nutr. Sci. Vitaminol. 2014, 60, 183-187. [CrossRef]

61. Chen, J.; He, J.; Wildman, R.P.; Reynolds, K.; Streiffer, R.H.; Whelton, P.K. A randomized controlled trial of dietary fiber intake on serum lipids. Eur. J. Clin. Nutr. 2006, 60, 62-68. [CrossRef]

62. Pins, J.J.; Geleva, D.; Keenan, J.M.; Frazel, C.; O'Connor, P.J.; Cherney, L.M. Do whole-grain oat cereals reduce the need for antihypertensive medications and improve blood pressure control? J. Fam. Pract. 2002, 51, 353-359.

63. Yusuf, S.; Dagenais, G.; Pogue, J.; Bosch, J.; Sleight, P. Vitamin E supplementation and cardiovascular events in high-risk patients. N. Engl. J. Med. 2000, 342, 154-160. [CrossRef]

64. Nicklas, T.A.; O’Neil, C.E.; Fulgoni, V.L., 3rd. Diet quality is inversely related to cardiovascular risk factors in adults. J. Nutr. 2012, 142, 2112-2118. [CrossRef]

65. Piercy, K.L.; Troiano, R.P.; Ballard, R.M.; Carlson, S.A.; Fulton, J.E.; Galuska, D.A.; George, S.M.; Olson, R.D. The Physical Activity Guidelines for Americans. JAMA 2018, 320, 2020-2028. [CrossRef]

66. Magee, L.; Hale, L. Longitudinal associations between sleep duration and subsequent weight gain: A systematic review. Sleep Med. Rev. 2012, 16, 231-241. [CrossRef]

67. Fulgoni, V.L., 3rd; Brauchla, M.; Fleige, L.; Chu, Y. Oatmeal-Containing Breakfast is Associated with Better Diet Quality and Higher Intake of Key Food Groups and Nutrients Compared to Other Breakfasts in Children. Nutrients 2019, 11, 964. [CrossRef]

68. O’Neil, C.E.; Nicklas, T.A.; Zanovec, M.; Cho, S. Whole-grain consumption is associated with diet quality and nutrient intake in adults: The National Health and Nutrition Examination Survey, 1999-2004. J. Am. Diet. Assoc. 2010, 110, 1461-1468. [CrossRef] 
69. Mann, K.D.; Pearce, M.S.; McKevith, B.; Thielecke, F.; Seal, C.J. Whole grain intake and its association with intakes of other foods, nutrients and markers of health in the National Diet and Nutrition Survey rolling programme 2008-11. Br. J. Nutr. 2015, 113, 1595-1602. [CrossRef]

70. Maki, K.C.; Slavin, J.L.; Rains, T.M.; Kris-Etherton, P.M. Limitations of observational evidence: Implications for evidence-based dietary recommendations. Adv. Nutr. 2014, 5, 7-15. [CrossRef]

71. Isaksson, H.; Tillander, I.; Andersson, R.; Olsson, J.; Fredriksson, H.; Webb, D.L.; Aman, P. Whole grain rye breakfast - sustained satiety during three weeks of regular consumption. Physiol. Behav. 2012, 105, 877-884. [CrossRef]

72. Gerard, P. Gut microbiota and obesity. Cell Mol. Life Sci. 2016, 73, 147-162. [CrossRef]

73. Blaut, M. Gut microbiota and energy balance: Role in obesity. Proc. Nutr. Soc. 2015, 74, 227-234. [CrossRef]

74. Sandberg, J.C.; Bjorck, I.M.E.; Nilsson, A.C. Effects of whole grain rye, with and without resistant starch type 2 supplementation, on glucose tolerance, gut hormones, inflammation and appetite regulation in an 11-14.5 hour perspective; a randomized controlled study in healthy subjects. Nutr. J. 2017, 16, 25. [CrossRef]

75. De Moura, F.F.; Lewis, K.D.; Falk, M.C. Applying the FDA definition of whole grains to the evidence for cardiovascular disease health claims. J. Nutr. 2009, 139, 2220S-2226S. [CrossRef]

76. Wang, Q.; Ellis, P.R. Oat beta-glucan: Physico-chemical characteristics in relation to its blood-glucose and cholesterol-lowering properties. Br. J. Nutr. 2014, 112, S4-S13. [CrossRef]

77. Calinoiu, L.F.; Vodnar, D.C. Whole Grains and Phenolic Acids: A Review on Bioactivity, Functionality, Health Benefits and Bioavailability. Nutrients 2018, 10, 1615. [CrossRef]

78. Nayak, B.; Liu, R.H.; Tang, J. Effect of processing on phenolic antioxidants of fruits, vegetables, and grains-A review. Crit. Rev. Food Sci. Nutr. 2015, 55, 887-919. [CrossRef]

(C) 2019 by the authors. Licensee MDPI, Basel, Switzerland. This article is an open access article distributed under the terms and conditions of the Creative Commons Attribution (CC BY) license (http://creativecommons.org/licenses/by/4.0/). 